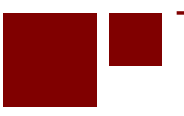

C E N T E R for RETIREMENT RES E A R C H at BOSTON COLLEGE

\title{
COGNITIVE IMPAIRMENT AND SOCIAL SECURITY'S REPRESENTATIVE PAYEE PROGRAM
}

\author{
Anek Belbase and Geoffrey T. Sanzenbacher \\ CRR WP 2016-12 \\ November 2016 \\ Center for Retirement Research at Boston College \\ Hovey House \\ 140 Commonwealth Avenue \\ Chestnut Hill, MA 02467 \\ Tel: 617-552-1762 Fax: 617-552-0191 \\ http://crr.bc.edu
}

Both of the authors are with the Center for Retirement Research at Boston College (CRR). Anek Belbase is a research fellow at the CRR. Geoffrey T. Sanzenbacher is a research economist at the CRR. The research reported herein was pursuant to a grant from the U.S. Social Security Administration (SSA) funded as part of the Retirement Research Consortium. The findings and conclusions expressed are solely those of the authors and do not represent the views of SSA, any agency of the federal government, or Boston College. Neither the United States Government nor any agency thereof, nor any of their employees, makes any warranty, express or implied, or assumes any legal liability or responsibility for the accuracy, completeness, or usefulness of the contents of this report. Reference herein to any specific commercial product, process or service by trade name, trademark, manufacturer, or otherwise does not necessarily constitute or imply endorsement, recommendation or favoring by the United States Government or any agency thereof.

(C) 2016, Anek Belbase and Geoffrey T. Sanzenbacher. All rights reserved. Short sections of text, not to exceed two paragraphs, may be quoted without explicit permission, provided that full credit, including $(\mathbb{C}$ notice, is given to the source. 


\begin{abstract}
About the Center for Retirement Research
The Center for Retirement Research at Boston College, part of a consortium that includes parallel centers at the University of Michigan and the National Bureau of Economic Research, was established in 1998 through a grant from the Social Security Administration. The Center's mission is to produce first-class research and forge a strong link between the academic community and decision-makers in the public and private sectors around an issue of critical importance to the nation's future. To achieve this mission, the Center sponsors a wide variety of research projects, transmits new findings to a broad audience, trains new scholars, and broadens access to valuable data sources.
\end{abstract}

Center for Retirement Research at Boston College

Hovey House

140 Commonwealth Ave

Chestnut Hill, MA 02467

Tel: 617-552-1762 Fax: 617-552-0191

http://crr.bc.edu

Affiliated Institutions:

The Brookings Institution

Syracuse University

Urban Institute 


\begin{abstract}
Social Security’s Representative Payee Program allows one individual to receive benefits on behalf of a retiree or disabled person who is incapable of managing them. In the case of retirees with cognitive impairment, the program could help prevent fraud by ensuring that Social Security benefits are immediately turned over to a capable individual. This paper seeks to answer three questions about the Representative Payee Program and its relationship to cognitive impairment. First, what share of individuals with cognitive impairment use a representative payee? Second, if individuals with cognitive impairment are not using a payee, what are they doing instead? Finally, is it possible to identify recipients with cognitive impairment who have no help managing their finances (through a representative payee or otherwise), a situation that makes them especially vulnerable to fraud?
\end{abstract}

This paper found that:

- Just over 9 percent of retirees with dementia, the most severe form of cognitive impairment, have a payee, while only 2 percent of those with mild cognitive impairment have one.

- Over 95 percent of retirees with dementia have some form of assistance with their financial management, whether it is a payee, a non-impaired spouse or child, a power of attorney, or through their residence in a nursing home. The comparable number for those with mild cognitive impairment is 85 percent.

- Retirees with spouses or kids living nearby are less likely to use a payee, indicating they may view family as substitutes for a payee.

- Less educated, non-white, and relatively isolated retirees are most likely to lack formal or informal means of assistance with their financial management.

The policy implications of this paper are:

- Most individuals with cognitive impairment seem to have an institution or individual available who could serve as a representative payee should an expansion of the program become desirable.

- Educating family and other caregivers about a primary benefit of the program - that the vulnerable person does not have access to his or her money - may help expand coverage. 


\section{Introduction}

According to the National Council on Aging, financial exploitation is one of the most common forms of elder abuse. Because individuals with dementia - the most severe form of cognitive impairment - cannot manage their finances, they must depend on others and are especially at risk of abuse (New York City Department of Aging, 2011). And people with mild cognitive impairment, while not uniformly at risk, have varying degrees of financial ability. While most lack the ability to detect simple fraud schemes, some even lack the ability to pay bills and manage everyday finances (Triebel et al., 2009; Martin et al., 2003). Social Security’s Representative Payee Program helps to mitigate the risk of financial abuse and fraud among retirees with cognitive impairment in two ways: 1 ) by limiting access to their benefit when they may be most vulnerable to fraud; and 2) by enforcing reporting requirements on the payees to ensure that they do not take advantage of the beneficiaries. The expectation is that all retirees with dementia and many retirees with mild cognitive impairment could benefit from the program.

But do they use this program? A quick look at the data suggests many do not. Despite the fact that over 10 percent of those 65 and older have dementia, just 1.5 percent of retirees over 65 have a payee (Anguelov, Ravida, and Weathers II, 2015; Herbert et al., 2013). But no study to date has attempted to identify how payee usage varies with the occurrence of cognitive impairment. To fill this gap in the literature, this paper seeks to answer three questions about cognitive impairment and the Representative Payee Program. First, what share of retirees with cognitive impairment use a representative payee, and how does it vary by the severity of impairment? Second, if these retirees are not using a payee, what are they doing instead? Finally, could correlates be useful to identify recipients with cognitive impairment who have no help managing their finances (through a representative payee or otherwise), which makes them especially vulnerable to fraud?

To answer these questions, this paper uses the Health and Retirement Study (HRS) linked to Respondent Cross-Year Benefits data to identify whether or not a retiree is using a payee. The paper then groups retirees into three buckets of cognitive impairment to see how payee use differs among them: 1) those without any signs of cognitive impairment; 2) those with mild cognitive impairment or memory issues, but not dementia; and 3) those with dementia. Although those with mild cognitive impairment may be unlikely to use a payee because their condition 
appears less severe, the evidence suggests at least some people with mild impairment may need one. And because they are unlikely to notice the decline, they could be especially unlikely to seek out help through a payee or any other means (Willis and Hsu, 2013).

But the discussion above indicates that even the majority of those with severe cognitive impairment do not have a payee. What do they do instead? Some may rely on caregivers as a substitute for a payee since, as cognitive impairment progresses from mild to severe, sufferers require assistance even with basic activities like bathing and dressing. This dependence means that many retirees with dementia will likely end up either in a nursing home or with some type of informal help. Financial management may be easier for those in a nursing home since in some cases their benefit may be applied directly to the stay. Fraud may also be less likely if the individual is not exposed to the wider community. For those with mild cognitive impairment, informal caregivers providing assistance with financial management may play a large role perhaps a non-impaired spouse or a child living nearby. Other people may set up powers of attorney and view this as a substitute for a payee (even though a power of attorney does not have the same safeguards as the Representative Payee Program). This paper will use variables available in the HRS to identify whether retirees with cognitive impairment have any of these sources of help.

Once the identification of a likely source of help - or lack of help - is complete, the project will identify correlates of having access to help with financial management. The above discussion yields a natural hierarchy of options: retirees using a representative payee are likely the least vulnerable, followed by those with other forms of assistance, and finally by those with no observed means of help. While this hierarchy is imperfect - for example, some children are sources of financial abuse - those without any help at all are in an especially precarious situation: living in the community, without a spouse or child nearby, and without a legal relationship formalized by a power of attorney.

To analyze who falls into which bucket, the paper will use probit models to identify correlates of individuals who have a representative payee and, separately, of individuals who have at least some observed means of help. These probit models take two forms: 1) using only information available to Social Security field offices, such as the dollar amount of the benefit, age, marital status, residence in a nursing home, and region of residence; and 2) using a more detailed specification including other demographic and individual characteristics. The idea 
behind the first approach is to provide Social Security with information that could help identify beneficiaries who lack help, while the second approach will provide a more detailed picture of the most vulnerable retirees.

The results suggest that while representative payee use is more common among those with dementia than those without it, only a small fraction of beneficiaries with dementia - about 9.1 percent - use one. As expected, the share with a payee is lower for those with mild cognitive impairment - 2 percent - and lower still for those without any impairment - just 0.5 percent. Fortunately, most retirees with cognitive impairment and without a payee seem to have other forms of assistance available.

Several results from the regression are worth highlighting. The first is that retirees seem to view children and spouses as substitutes for a payee instead of as potential payees: married retirees and those with children nearby are less likely to have a payee than those who are more isolated. The second result is that the payee program seems to serve the most vulnerable individuals, for example those with lower Social Security benefits or less education. But, when vulnerable retirees do not have a payee, they are also more likely to have no other form of help, suggesting the payee program may serve as a last resort source of help.

The paper proceeds as follows. The next section describes the data as well as the study's methodology for identifying dementia and sources of financial assistance, and it provides descriptive results. The next section presents regression results. The final section concludes that while vulnerable individuals are most likely to have a payee, vulnerable individuals are also most likely to have no source of informal assistance.

\section{Data and Descriptive Results}

Data from this project come from the Health and Retirement Survey (HRS) linked to restricted Social Security Respondent Cross-Year Benefits records that allow the identification of representative payee use. To limit the sample to retirees at risk of developing cognitive impairment, the HRS sample is restricted only to observations where the individual is over age 70 and receiving a Social Security retirement benefit. Workers who have received disability or SSI at any time are excluded. For ease of analysis, the paper focuses on a single observation for each sample member. The observation chosen is either when an individual is in their last wave 
of the HRS, i.e., before they exited the sample because of death or attrition, or in Wave 10, whichever is earlier.

These restrictions reduce the number of individuals analyzed from the full HRS universe of 37,317 individuals to 5,624 individuals who have all the variables ultimately used in the regression analysis, as is shown in detail in Table 1 . Table 2 provides basic descriptive statistics for this sample by age and shows that older members of the sample are slightly less educated, more likely to be female, less likely to be married, and more likely to be widowed. The table illustrates one of the problems individuals face as they become older and more likely to have dementia: they also simultaneously become less likely to have a spouse around to help.

\section{Identifying Cognitive Impairment}

To identify cognitive impairment, the paper divides the sample into three groups, those with: 1) no observed cognitive decline; 2) mild cognitive impairment; and 3) dementia. To create these groups, the project relies on the methodology of Hurd et al. (2013) to identify individuals likely to have mild cognitive impairment or dementia. In Hurd et al., the authors recognize that the HRS does not have a direct measure of dementia for all members of the sample. ${ }^{1}$ To create one, the authors started with an HRS subsample that did have a direct measure - a sample given detailed cognitive assessments during the Aging, Demographics, and Memory Study (ADAMS) who were either diagnosed as having no impairment, mild cognitive impairment, or dementia. Once individuals with mild cognitive impairment or dementia were identified in this subsample, the authors ran an ordered probit on the diagnosis with the independent variables available in the full HRS sample. The coefficients from this regression were then used to predict the likelihood of dementia or cognitive impairment for the entire HRS sample. The present study identifies individuals as having no impairment, mild cognitive impairment, and dementia based on which outcome is the most likely according to the regression predictions.

Of course, this indirect method may misidentify some people who have dementia or mild cognitive impairment but who do not have the characteristics identified by Hurd that are typically predictive of these conditions. For this reason, the study adds any individuals who

\footnotetext{
${ }^{1}$ Although in the most recent wave, a question on Alzhiemer's has been added.
} 
answered HRS questions indicating memory problems but who were not identified by the Hurd et al. approach. In particular, we identify people as experiencing memory problems if they: 1) cannot remember the correct date; 2) failed in two attempts counting backwards from 86; 3) failed in two attempts counting backwards from 20; or 4) remembered at most one word from a list of 10 words. Figure 1 breaks down the sample by the types of cognitive impairment and, in one case, how it was identified. It shows that about 10 percent have dementia and 35 percent have mild cognitive impairment, with about half of those with mild cognitive impairment identified using the Hurd approach and the other half using the memory based approach.

Figure 2 shows how the incidence of mild cognitive impairment and dementia change by age and indicates, as expected, that the incidence of both increase as individuals get older. Just 2.7 percent of those at the bottom end of the study's age range - 70-74 - have dementia and about one-third have mild cognitive impairment. But for those age 85 and over, 25.6 percent are identified as having dementia and 48.3 have mild cognitive impairment, meaning over 70 percent have some kind of cognitive impairment.

Table 3 provides descriptive statistics for the sample by cognitive impairment status and illustrates some differences between those with mild cognitive impairment and dementia. Those with dementia tend to be older, less educated, and more likely to be female and widowed than those with mild cognitive impairment or with no cognitive impairment. In essence, those with dementia tend to be from a more vulnerable population. Table 3 also previews the fact that as cognitive impairment increases from none to mild to dementia, sample members are more likely to have resident children.

One issue with the above measures of cognitive impairment is that they are not based on a medical diagnosis. In other words, if the study finds few people with mild cognitive impairment or dementia use a representative payee, it could be that few actually do or it could be that the assignment of who actually has impairment is not correct. This concern is somewhat alleviated by the fact that the internal validity of the Hurd model is good - over 85 percent of cases of cognitive impairment were correctly classified. But still, misidentification remains a concern. 
To alleviate this concern, the paper uses Medicare claims data to identify individuals who actually have a diagnosis of dementia and compare this to the share identified in the study. ${ }^{2}$ Due to data restrictions, these data cannot be merged with the representative payee data, and these individuals will not be included in either of our cognitive impairment groups because they cannot be included in the main analysis. However, they can be used to check for consistency with the measures described above.

Table 4 shows that considerable disparity exists between the share of the sample having dementia as identified using the Hurd approach and the share with dementia as identified in the Medicare claims data. The Hurd approach identifies about 10 percent as having dementia, versus 16 percent in the Medicare claims analysis. And this difference is actually bigger than it appears, since both approaches include some individuals left out of the other. Indeed, about 11 percent of our sample is identified in the Medicare claims data as having dementia but not using the Hurd approach. Then again, this finding is not surprising - Østbye et al. (2008) report similar levels of disagreement when comparing claims data to the HRS ADAMs study used to form the Hurd predictions. And Taylor et al. (2009) find that claims data over-count the true prevalence of dementia.

In any case, if the definition used in the current paper is expanded to include mild cognitive impairment as defined above, then just 4 percent of the sample is identified as having dementia in the Medicare claims data but not as having impairment in this study. This provides further justification for our examination of those with mild cognitive impairment, since it is possible some of these individuals actually have a more severe condition.

\section{Identifying Sources of Assistance with Financial Management}

The first goal is to identify the share of retirees with mild cognitive impairment and dementia who are using a representative payee. Individuals with a payee are identified using the restricted Respondent Cross-Year Benefits file, derived from the Social Security's Master Beneficiary Record, and are linked to the core HRS. Retirees are said to have a payee if they have a non-missing value for the "Custody Code," which indicates their living situations (e.g., with spouse, with natural or adopted child or stepchild, or non-profit non-mental institution, etc.).

\footnotetext{
${ }^{2}$ Dementia was identified in the CMS data by the presence of an ICD-9 diagnosis code starting in 290, 331, or 797 in the inpatient, outpatient, or physician office setting.
} 
Figure 3 shows how payee use differs among those with no observed cognitive impairment, those with mild cognitive impairment, and those with dementia and illustrates that 9 percent of those with dementia use a payee. As expected, those with mild cognitive impairment fall in the middle of the two other groups, showing that some may be so impaired that they need a payee, though not as many as those with dementia.

Given that the majority of retirees with cognitive impairment have no payee, the next task is to identify what they do instead. The first type of help considered is having a spouse who has no sign of mild cognitive impairment or dementia. Another common source of help may be the retiree's children who are helping them with either Instrumental Activities of Daily Living (IADLs) or Activities of Daily Living (ADLs). Familial help may be especially common for individuals still residing in the community. Individuals in nursing homes represent a slightly different situation: their need for financial management may be somewhat less, because in many cases their benefit will be paid directly to the nursing home. The best case scenario would be to have the nursing home serve as an institutional representative payee (which should result in the retiree being flagged as having a payee above), but this may not occur. For this reason, we flag retirees staying in a nursing home as individuals who likely have some form of assistance with managing their finances.

The final source of potential financial management is that the retiree has designated an individual with power of attorney. Here, the paper is forced to take an admittedly imperfect approach to measuring the availability of help because the HRS does not ask its full sample specifically about financial powers of attorney. ${ }^{3}$ Instead, it asks about whether the individual has designated a durable power of attorney in the context of health. We flag retirees who have made such a designation, since it indicates that the individual has taken steps to assign someone else legal authority over some of their affairs.

Table 5 shows the share of retirees who have each of the sources of help and the share with at least one of the sources, sorted by cognitive impairment status. The results shows that retirees with dementia are more likely than those with mild cognitive impairment to reside in a nursing home, to have a resident child, and to have a child helping with either IADLs or AIDLs, while both groups are equally likely to have assigned a power of attorney. One source of help

\footnotetext{
${ }^{3}$ A new experimental module does ask about financial power of attorney, but it was asked to only a subset of the population and the number of individuals in our sample asked the question is very small.
} 
that is more common among retirees with mild cognitive impairment than among those with dementia is having a non-impaired spouse, which makes sense given they tend to be younger than those with dementia. Taking all the sources of help together, those with mild cognitive impairment are, as expected, less likely than those with dementia to have some observed form of help, with shares of 85 percent and 95 percent, respectively. ${ }^{4}$

While this finding is encouraging, none of the non-representative payee arrangements is a substitute for Social Security’s direct handoff of money to a capable individual with recordkeeping responsibilities facilitated by the representative payee program. For example, children are occasionally abusers (Aciemo et al., 2010), and no one keeps track of their spending if they do not have an official representative payee designation, which does include tracking spending using the benefit. Still, on average, individuals with at least one type of help with their finances are likely less vulnerable than those without any help.

\section{Data on Correlates of the Availability of Help}

The final goal is to identify the characteristics of those with a representative payee and of those with at least some observed form of help. To accomplish this, the paper identifies two sets of potential correlates with the presence of assistance: 1) those variables that would be available to a Social Security field office; and 2) other variables that could affect the availability of assistance.

The relationship between assistance and the variables visible to Social Security field offices is important because it can be based on data that could actually be applied in the field. These variables include the recipient's age, marital status, U.S. Census region of residence, ${ }^{5}$ whether they live in a nursing home, and their Social Security Primary Insurance Amount. If a relationship exists between these variables and the use of a payee or the availability of other forms of help, then field offices could use the presence of these indicators to flag and reach out to vulnerable seniors.

\footnotetext{
${ }^{4}$ Those with no cognitive impairment are included for comparison and appear to often have a source of help even though they likely do not need one - this result is a function of the fact that they are much more likely to have nonimpaired spouses. Other forms of help are less likely as expected.

${ }^{5}$ While restricted data on state of residence is available in the HRS, it cannot be merged with the restricted data used to identify representative payee use.
} 
Other variables that are not a part of standard Social Security records may also be interesting and may shed light on how people use the representative payee program. For example, people with a non-impaired spouse or with children nearby (defined as living within 10 miles) might tend to eschew the Representative Payee Program and use these informal family relationships as substitutes. But, information on the impairment of a spouse or on children helping would not be available to Social Security field offices. Other variables fitting this mold that are used in the regression analysis include information on children's marital status (single children may be more able to help) and the retiree's education, race, religious affiliation (Catholic or not), and residence in a county with fewer than 250,000 people. Any one of these variables may determine how isolated individuals are and how likely they are to have any means of assistance, and all of these variables can be derived easily from the core HRS questionnaire. Another variable of interest is whether or not the individual has long-term care insurance, which would indicate some level of financial sophistication and a degree of foresight regarding the possibility of cognitive decline.

Table 6 provides evidence on how these characteristics differ for those with mild and severe cognitive impairment based on the level of help someone is receiving: a representative payee only, at least some assistance (including a payee), and no assistance. For comparison, the table also provides data on the average member of the sample population. The first takeaway from the table is that those with a payee are much more likely than the average to be "isolated," meaning that they are not married and do not have a child living within 10 miles. Those with a payee are also less educated, have lower lifetime earnings as measured by their PIA, and are much less likely to have long-term care insurance. In other words, those with a payee seem more vulnerable than those without one.

Turning to those who receive no assistance with their financial matters, most of these same characteristics are present, albeit to a lesser extent. This finding seems to suggest that vulnerable individuals who do not get a payee are also less likely to find another form of help. To explore this relationship further, a regression analysis is useful.

\section{Regression Results}

The regression analyses conducted in this paper are probits that use the dependent variable as either: 1) an indicator for whether the individual with cognitive impairment had a 
representative payee; or 2) an indicator for whether the individual with cognitive impairment had any form of assistance identified in Table 5 (including a representative payee). The regressions are presented in Table 7 for representative payee use and Table 8 for receiving any kind of assistance. Each table presents results in four ways: 1) using variables available to SSA field offices to identify those with dementia; 2) using a full set of variables for those with dementia; 3) using variables available to SSA field offices for those with any cognitive impairment; and 4) using a full set of variables for those with any cognitive impairment.

The results for retirees with dementia in the first column of Table 7 - which displays only variables likely to be available to field workers - indicate that having a spouse or being widowed significantly reduces the likelihood of having a representative payee relative to those who never married. Taken together, these results are consistent with couples using the spouse as a substitute for a payee but not replacing them with a payee at their death. On the other hand, retirees in nursing homes are significantly more likely to have a payee, though no significant relationship between age or PIA is found. When the sample is expanded to include those with milder cognitive impairment (column 3), the main difference is that having a lower PIA makes an individual more likely to have a representative payee. The results in Table 6 suggest that recently widowed retirees and those living in their community instead of a nursing home may be more in need of a payee than others. The fact that lower PIAs are associated with a higher likelihood of having a payee suggests that the program may be serving more vulnerable individuals.

When the variables are expanded to include variables not available to field workers (columns 2 and 4), the results also illustrate that family are substitutes for a payee and that vulnerable individuals use a payee. Focusing on the results for the full sample of those with any type of cognitive impairment, ${ }^{6}$ individuals who are "isolated" - they have no spouse and no child within 10 miles - are significantly more likely to have a payee than others. Additionally, people with less education are more likely to use a payee, but the coefficient on PIA has become insignificant. This result suggests that the effect of earnings on payee use is working through education. On the whole, the findings suggest that vulnerable individuals without family nearby and with little education are more likely to use the payee program than others.

\footnotetext{
${ }^{6}$ The results are similar in magnitude for the dementia sample but less likely to be significant due to sample size
} 
Table 8 presents the results when the dependent variable is changed from representative payee use to just having some form of assistance, representative payee or otherwise. Due to the small sample size for the dementia-only group, it is useful to examine those with any cognitive impairment. The conclusions stand in contrast to those presented in Table 7, when looking at specification 4, which uses a full set of variables. Retirees who are isolated are significantly less likely to have help than those with a spouse or children nearby. And unlike the regression for representative payee only, having less than a high school degree or only a high school degree are both associated with significantly lower likelihoods of having some help than someone with a college degree. Other variables that are significant include being Catholic and living in a county with fewer than 250,000 people, both of which are associated with being more likely to have at least some form of assistance. Perhaps these variables are capturing communities where more individuals are available to serve as payees or at least as powers of attorney.

In any case, the results presented in Table 7 and 8 describe an interesting situation. On the one hand, people are more likely to have a payee if they have less education or are living without a spouse or children nearby. This suggests the Representative Payment Program is serving the most vulnerable retirees. The regressions also suggest that people tend to view spouses and children as substitutes for a payees, not as individuals who could serve as a payee. In some ways, this makes sense. Participating in the representative payee program has reporting requirements that the more informal methods a child or spouse may engage in (joint checking accounts or simply handing over the checkbook) do not have. Individuals providing informal assistance may see no need to add to their burden. But, these informal approaches leave the retiree who has cognitive impairment with access to their money and vulnerable to fraud from outside sources. The Representative Payee Program helps ensure that this does not occur by providing the caregiver with direct access to the retirees benefit.

\section{Conclusion}

The Representative Payee Program is designed to make those incapable of managing their finances less vulnerable to fraud by putting the money directly in the hands of a capable individual who has a responsibility to keep accurate records. Given that the goal of the program is to help the vulnerable manage their benefits, the most common users of the program are actually those on disability and SSI. But retirees with cognitive decline and dementia are 
becoming a larger group, and understanding how they relate to the Representative Payee Program is important.

The results suggest that the majority of retirees with mild cognitive decline and dementia do not have a payee. At the same time, they are much more likely to use the Representative Payee Program than retirees without these conditions. Payee use increases from 2 percent of those with mild cognitive impairment to 9.1 percent for those with dementia. The results also suggest that the program tends to serve those who need it the most - either people without a spouse or children nearby and people who have little education. For those who do not have a payee, the help of a non-impaired spouse, children, or other community members seem to serve as substitutes, albeit imperfect ones, for a payee. Very few people with cognitive impairment have no help, but those who do tend to come from the same groups that are more likely to have a payee - those with little education and with no kids nearby. This highlights the importance of the representative payee program, which appears to be serving as a last resort for some.

Going forward, as the first baby boomers approach their eighties in 2026, the population of retirees with dementia is likely to grow considerably, and more payees may accordingly need to be found. The findings in this paper imply that most people will already have someone nearby ready to serve. Almost all retirees with dementia who were not using a payee were either in a nursing home, residing with a non-impaired spouse, had a child helping out, or had assigned power of attorney to somebody. The key will be finding out what can be done to bring more of the people currently helping someone with cognitive decline into the Representative Payee Program. 


\section{References}

Aciemo, Ron, Melba A. Hernandez, Ananda B. Amstadler, Heidi S. Resnick, Kenneth Steve, Wendy Muzzy, and Dean G. Kilpatrick. 2010. "Prevalence and Correlates of Emotional, Physical, Sexual, and Financial Abuse and Potential Neglect in the United States: The National Elder Mistreatment Study.” American Journal of Public Health 100(2): 292297.

Alzheimer’s Association. n.d. “Stages of Alzheimer’s.” Chicago, IL. Available at: http://www.alz.org/alzheimers_disease_stages_of_alzheimers.asp

Anguelov, Chris E., Gabriella Ravida, and Robert R. Weathers II. 2015. “Adult OASDI Beneficiaries and SSI Recipients Who Need Representative Payees: Projections for 2025 and 2035.” Social Security Bulletin 75(2): 1-17.

Herbert, Liesi E., Jennifer Weuve, Paul A. Scherr, and Denis A. Evans. 2013. “Alzheimer Disease in the United States (2010-2050) Estimated Using the 2010 Census.” Neurology 80(19): 1778-1783.

Hurd, Michael D., Paco Martorell, Adeline Delavande, Kathleen J. Mullen, and Kenneth M. Langa. 2013. "Monetary Costs of Dementia in the United States.” The New England Journal of Medicine 368(14): 1326-1334.

Hsu, Joanne W. and Robert Willis. 2013. “Dementia Risk and Financial Decision Making by Older Households: The Impact of Information.” Journal of Human Capital 7(4): 340377.

New York City Department for the Aging, Lifespan of Greater Rochester, Inc., and Weill Cornell Medical Center of Cornell University. 2011. "Under the Radar: New York State Elder Abuse Prevalence Study.” Available at: http://ocfs.ny.gov/main/reports/Under\%20the\%20Radar\%2005\%2012\%2011\%20final\%2 Oreport.pdf

Martin, Roy C., Shannon M. Annis, Laurie Z. Darling, Virginia Wadley, Lindy Harrell, Daniel C. Marson. 2003. "Loss of Calculation of Abilities in Patients with Mild and Moderate Alzheimer Disease.” Archives of Neurology 60(11): 1585-1589.

Østbye, Truls, Donald H. Taylor Jr., Elizabeth C. Clipp, Lynn Van Scoyoc, and Brenda L. Plassman. "Identification of Dementia: Agreement among National Survey Data, Medicare Claims, and Death Certificates.” Health Services Review 43(1): 313-326.

Plassman, B. L., K. M. Langa, G. G Fisher, S. G. Heeringa, D. R. Weir, M.B. Ofstedal, J. R. Burke, M. D. Hurd, G. G. Potter, W. L. Rodgers, D. C. Steffens, R. J. Willis, and R. B. Wallace. 2007. "Prevalence of Dementia in the United States: The Aging Demographics and Memory Study.” Neuroepidemology 29(1-2): 125-132. 
Sperling, Reisa A., Paul S. Aisen, Laurel A. Beckett, David A. Bennett, Suzanne Craft, Anne M. Fagan, Takeshi Iwatsubo, Clifford R. Jack, Jeffrey Kaye, Thomas J. Montine, Denise C. Park, Eric M. Reiman, Christopher C. Rowe, Eric Siemers, Yaakov Stern, Kristine Yaffe, Maria C. Carrillo, Bill Thies, Marcelle Morrison-Bogorad, Molly V. Wagster, and Creighton H. Phelps. 2011. "Toward Defining the Preclinical Stages of Alzheimer's Disease: Recommendations from the National Institute on Aging and the Alzheimer's Association Workgroup.” Alzheimer's and Dementia 7(3): 280-292.

Taylor, Donald H., Truls Østbye, Kenneth M. Langa, David Weir, and Brenda L. Plassman. 2009. "The Accuracy of Medicare Claims Data as an Epidemiological Tool: The Case of Dementia Revisted.” Journal of Alzheimer's Disease 17(4): 807-815.

Triebel, K.L., R. Martin, H. R. Griffith, J. Marceaux, O. C. Okonkwo, L. Harrell, D. Clark, J. Brockington, A. Bartolucci, and D. C. Marson. 2009. "Declining Financial Capacity in Mild Cognitive Impairment: A 1-year Longitudinal Study.” Neurology 73(12): 298-234. 
Figure 1. Share of Sample with Cognitive Impairment by Source

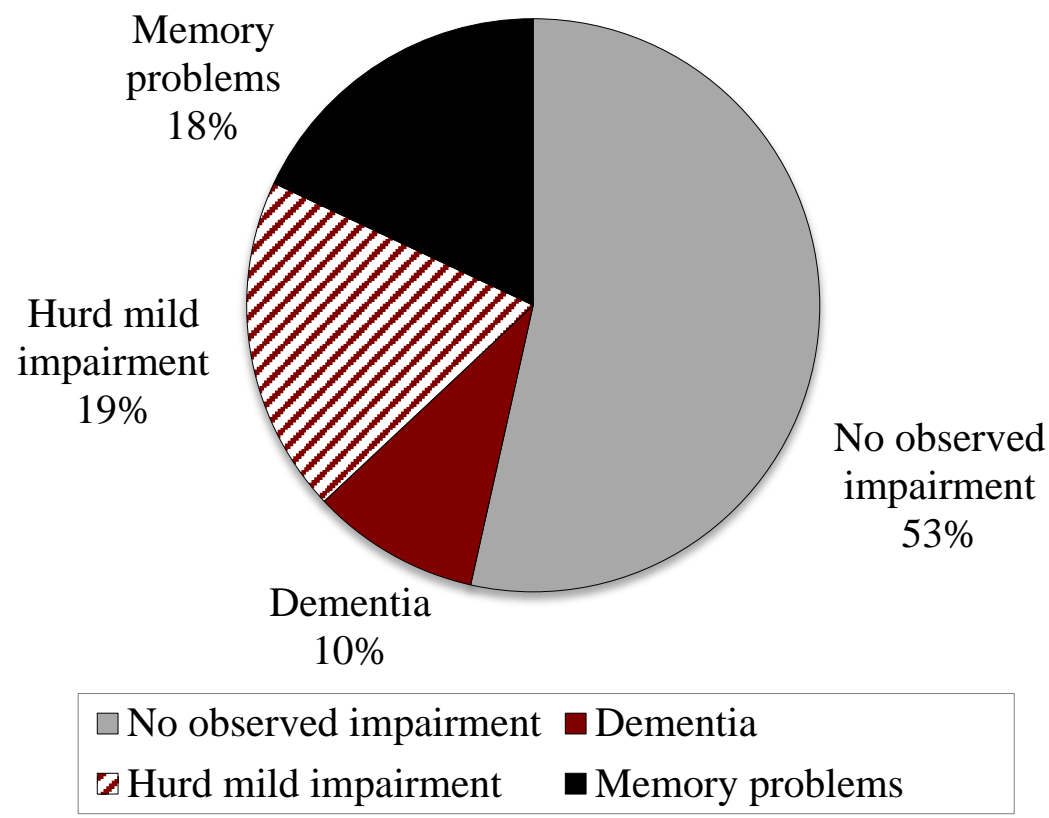

Source: Authors' calculation from the Health and Retirement Study (HRS), Waves 1-10.

Figure 2. Share of Sample with Mild Cognitive Impairment or Dementia by Age

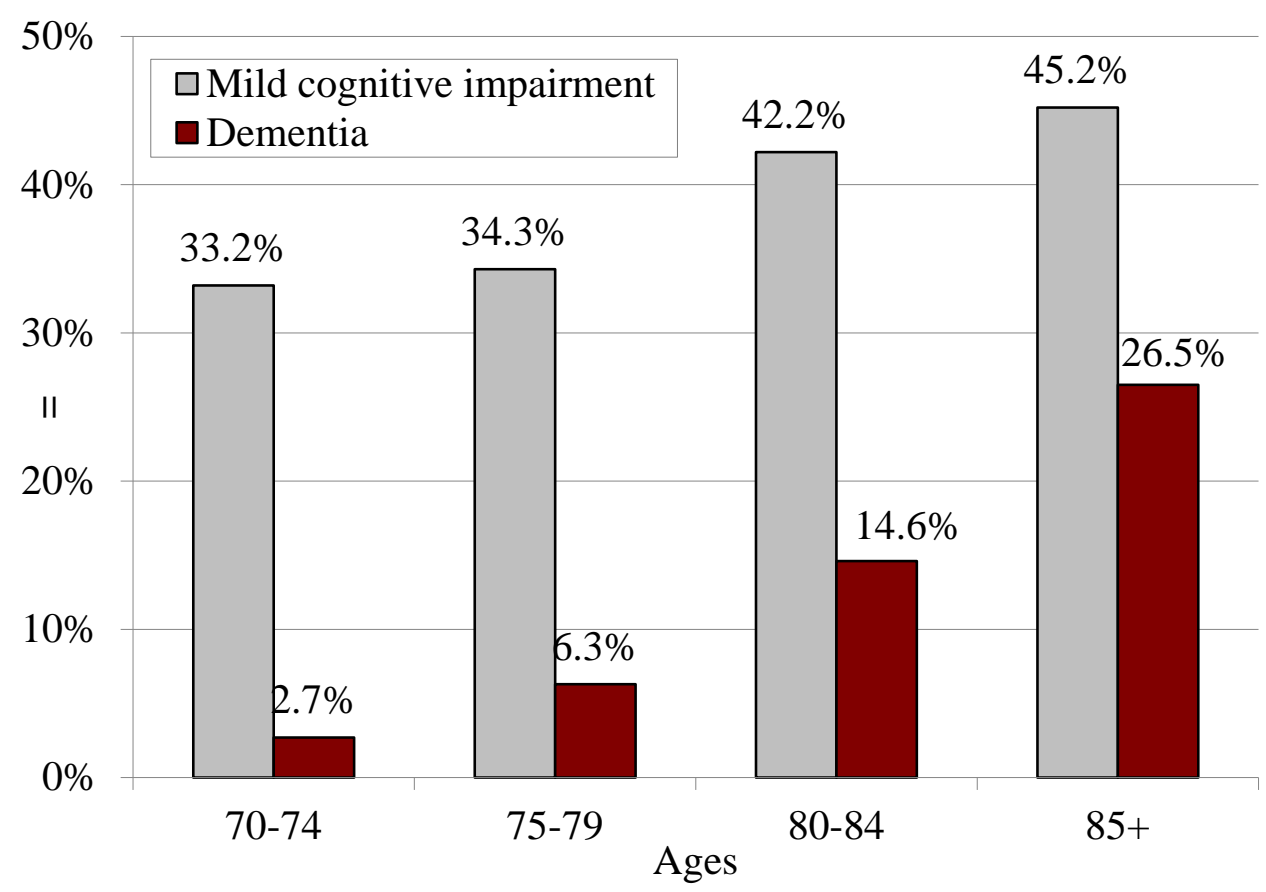

Sources: Authors' calculation from the HRS, Waves 1-10; and Hurd et al. (2013). 
Figure 3. Share of Sample using a Payee by Cognitive Impairment Status

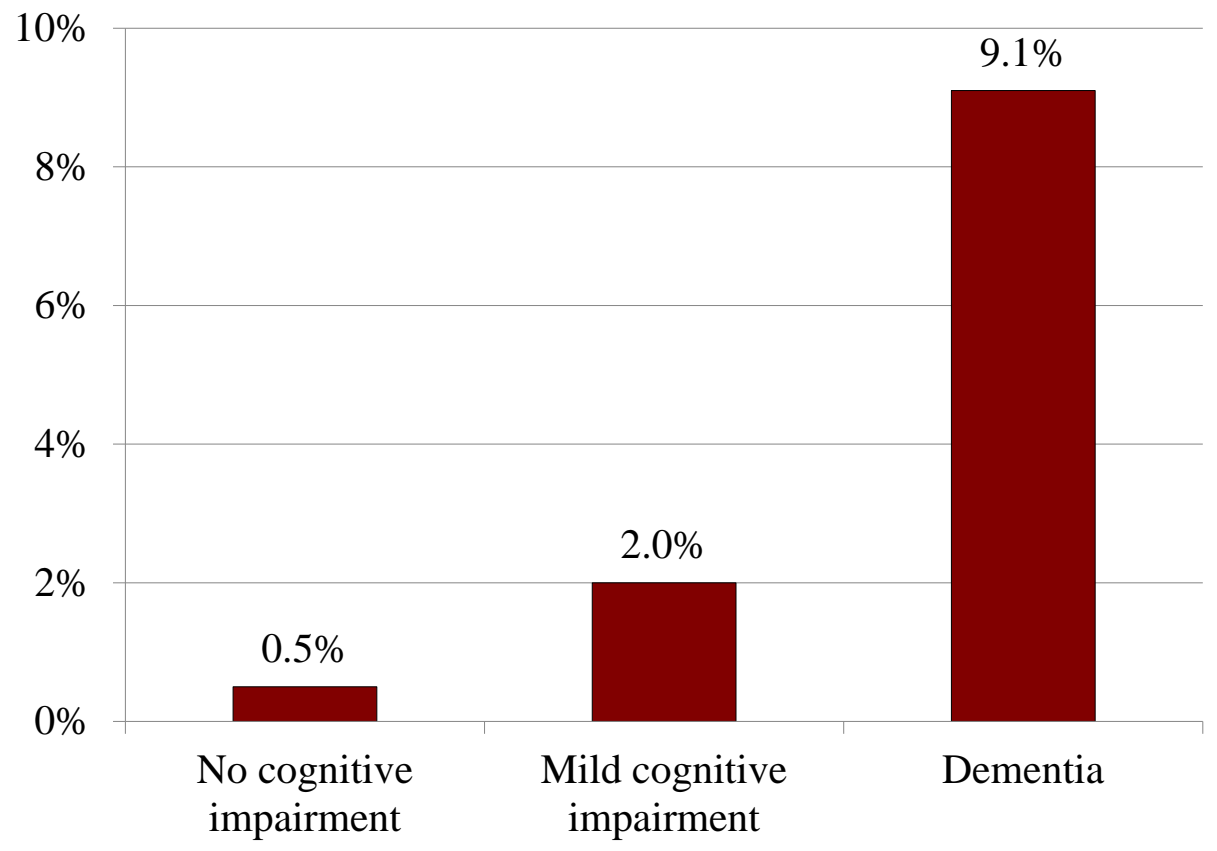

Sources: Authors' calculation from the HRS, Waves 1-10; and Hurd et al. (2013). 
Table 1. Effect of Sample Restrictions on Sample Size

\begin{tabular}{lc}
\hline Restrictions & Sample remaining \\
\hline Full HRS sample & 37,317 \\
Age 70+ in last survey wave & 17,745 \\
Has restricted SSA link & 11,407 \\
Partially/fully retired with PIA & 6,196 \\
Not receiving SSI or SSDI & 5,999 \\
Has full set of regression variables & 5,624 \\
Has cognitive impairment & 2,615 \\
\hline
\end{tabular}

Source: Authors' calculation from the HRS, Waves 1-10.

Table 2. Descriptive Statistics by Age

\begin{tabular}{lcccc}
\hline & \multicolumn{4}{c}{ Age groups } \\
\cline { 2 - 5 } & $70-74$ & $75-79$ & $80-84$ & $85+$ \\
\hline Average age & 72.0 & 76.9 & 81.8 & 88.5 \\
Educational shares & & & & \\
$\quad$ No degree & $20.3 \%$ & $22.4 \%$ & $22.8 \%$ & $26.3 \%$ \\
$\quad$ GED/high school & 57.3 & 54.3 & 52.1 & 52.3 \\
$\quad$ Further schooling & 22.4 & 23.2 & 25.0 & 21.4 \\
Share male & 47.8 & 48.5 & 50.8 & 44.0 \\
Share married & 63.2 & 60.2 & 56.6 & 35.5 \\
Share widowed & 20.0 & 27.8 & 34.5 & 56.5 \\
Share divorced/separated & 10.7 & 7.6 & 5.4 & 4.4 \\
Children & & & & \\
$\quad$ Average number & 3.7 & 3.7 & 3.8 & 3.4 \\
$\quad$ Resident child & $16.2 \%$ & $16.4 \%$ & $13.7 \%$ & $15.4 \%$ \\
$\quad$ Child nearby & 53.8 & 56.9 & 57.4 & 54.5 \\
Number of observations & 2,025 & 1,693 & 1,103 & 803 \\
\hline
\end{tabular}

Source: Authors' calculation from the HRS, Waves 1-10. 
Table 3. Descriptive Statistics by Cognitive Status

\begin{tabular}{lccc}
\hline & $\begin{array}{c}\text { No evidence } \\
\text { of impairment }\end{array}$ & $\begin{array}{c}\text { Mild cognitive } \\
\text { impairment }\end{array}$ & Dementia \\
\hline Average age & 76.3 & 78.4 & 83.1 \\
Educational shares & & & \\
$\quad$ No degree & $15.2 \%$ & $28.9 \%$ & $36.6 \%$ \\
$\quad$ GED/high school & 56.6 & 54.2 & 46.2 \\
$\quad$ Further schooling & 28.3 & 16.9 & 17.2 \\
Share male & 45.2 & 53.3 & 43.6 \\
Share married & 59.8 & 56.0 & 45.6 \\
Share widowed & 26.8 & 31.6 & 45.8 \\
Share divorced / separated & 7.9 & 8.0 & 6.7 \\
Children & & & \\
$\quad$ Average number & 3.6 & 3.8 & 3.7 \\
$\quad$ Living with child & $13.4 \%$ & $17.0 \%$ & $23.2 \%$ \\
$\quad$ Child nearby & 54.9 & 56.7 & 54.6 \\
Average PIA & $\$ 1,225.5$ & $\$ 1,169.9$ & $\$ 1,087.0$ \\
Number of observations & 3,009 & 2,080 & 535 \\
\hline
\end{tabular}

Source: Authors' calculation from the HRS, Waves 1-10.

Table 4. Comparison of Cognitive Impairment across Data Sources

\begin{tabular}{lcc|cc}
\hline & \multicolumn{3}{c}{ Cognitive impairment group } \\
\cline { 2 - 5 } & \multicolumn{2}{c}{ Dementia only } & \multicolumn{2}{c}{ Any cognitive impairment } \\
\cline { 2 - 5 } & Observations & Share & Observations & Share \\
\hline Impairment in both sources & 296 & $5.7 \%$ & 661 & $12.7 \%$ \\
CMS dementia diagnosis only & 604 & 11.6 & 239 & 4.6 \\
Impairment in this study only & 214 & 4.1 & 1,796 & 34.4 \\
No impairment in either & 4,104 & 78.7 & 2,522 & 48.3 \\
\hline Total & $\mathbf{5 , 2 1 8}$ & $\mathbf{1 0 0 \%}$ & $\mathbf{5 , 2 1 8}$ & $\mathbf{1 0 0 \%}$ \\
\hline
\end{tabular}

Note: The 5,218 observations in this table exclude 406 HRS observations that were not linked to CMS data. Dementia was identified in the CMS data by the presence of an ICD-9 diagnosis code beginning in of 290, 331, or 797 in the inpatient, outpatient, or physician office setting.

Source: Authors' calculation from the HRS, Waves 1-10 linked to Medicare Claims Data. 
Table 5. Available Outside Assistance, by Cognition Status

\begin{tabular}{lccc}
\hline Share with... & $\begin{array}{c}\text { No evidence } \\
\text { of impairment }\end{array}$ & $\begin{array}{c}\text { Mild cognitive } \\
\text { impairment }\end{array}$ & Dementia \\
\hline Representative payee & $0.5 \%$ & $2.0 \%$ & $9.1 \%$ \\
Nursing home care & 0.7 & 3.2 & 28.7 \\
Non-impaired spouse & 44.2 & 37.2 & 29.1 \\
Resident child & 13.4 & 17.3 & 23.4 \\
Help from a child & 4.5 & 12.2 & 36.6 \\
Power of attorney & 67.3 & 62.9 & 63.2 \\
Any form of assistance & 86.3 & 85.0 & 95.1 \\
Number of observations & 2,542 & 1,756 & 492 \\
\hline
\end{tabular}

Source: Authors' calculation from the HRS, Waves 1-10. 
Table 6. Descriptive Statistics of Impaired Sample, by Available Assistance

\begin{tabular}{|c|c|c|c|c|}
\hline & $\begin{array}{l}\text { Representative } \\
\text { payee }\end{array}$ & $\begin{array}{c}\text { Any form } \\
\text { of assistance }\end{array}$ & $\begin{array}{c}\text { No } \\
\text { observable } \\
\text { assistance }\end{array}$ & $\begin{array}{c}\text { Average } \\
\text { sample member }\end{array}$ \\
\hline \multicolumn{5}{|l|}{ Domestic environment } \\
\hline Married & $30.3 \%$ & $56.4 \%$ & $45.4 \%$ & $53.8 \%$ \\
\hline Widowed & 44.9 & 33.1 & 40.0 & 34.5 \\
\hline Isolated & 36.0 & 11.3 & 20.0 & 13.5 \\
\hline History of divorce/being widowed & 12.4 & 7.6 & 9.9 & 8.1 \\
\hline Has kids & 82.0 & 96.0 & 93.8 & 95.2 \\
\hline Has unmarried kids & 61.8 & 62.1 & 58.8 & 61.6 \\
\hline Nursing home care & 39.3 & 8.3 & -- & 8.1 \\
\hline \multicolumn{5}{|l|}{ Economic } \\
\hline Has long-term care insurance & 7.9 & 11.5 & 12.6 & 11.5 \\
\hline Average PIA & $\$ 1,017.4$ & $\$ 1,162.9$ & $\$ 1,130.5$ & $\$ 1,152.9$ \\
\hline \multicolumn{5}{|l|}{ Education } \\
\hline No degree & $48.3 \%$ & $28.7 \%$ & $36.3 \%$ & $30.5 \%$ \\
\hline GED/high school & 40.4 & 53.1 & 52.1 & 52.5 \\
\hline Further schooling & 11.2 & 18.2 & 11.6 & 16.9 \\
\hline \multicolumn{5}{|l|}{ Demographics } \\
\hline Average age & 81.1 & 79.6 & 78.0 & 79.4 \\
\hline Male & $42.7 \%$ & $51.7 \%$ & $51.1 \%$ & $51.3 \%$ \\
\hline Non-white & 28.1 & 21.5 & 32.8 & 23.5 \\
\hline Catholic & 30.3 & 26.4 & 22.5 & 26.0 \\
\hline $\begin{array}{l}\text { County population } \\
\text { less than } 250,000\end{array}$ & 41.6 & 31.3 & 28.6 & 31.2 \\
\hline Number of observations & 89 & 2,121 & 405 & 2,615 \\
\hline
\end{tabular}

Source: Authors' calculation from the HRS, Waves 1-10. 
Table 7. Marginal Effects for Representative Payee Use, by Cognitive Impairment Status

\begin{tabular}{|c|c|c|c|c|}
\hline \multirow[b]{2}{*}{ Representative payee } & \multicolumn{2}{|c|}{ Imputed dementia } & \multicolumn{2}{|c|}{ Any sign of impairment } \\
\hline & $\begin{array}{c}(1) \\
\text { SSA }\end{array}$ & $\begin{array}{c}(2) \\
\text { Full } \\
\text { specification } \\
\end{array}$ & $\begin{array}{c}(3) \\
\text { SSA }\end{array}$ & $\begin{array}{c}\text { (4) } \\
\text { Full } \\
\text { specification }\end{array}$ \\
\hline Married & $-0.112 * * *$ & - & $-0.036 * * *$ & - \\
\hline Widowed & $-0.080 * *$ & - & $-0.020 * * *$ & - \\
\hline Isolated & - & 0.058 & - & $0.017^{*}$ \\
\hline History of divorce/being widowed & - & 0.062 & - & $0.025 *$ \\
\hline Has children & - & $-0.273 * *$ & - & $-0.082 * *$ \\
\hline Has unmarried children & - & 0.030 & - & $0.011 * *$ \\
\hline Nursing home care & $0.087 * * *$ & $0.067 * *$ & $0.118 * * *$ & $0.102 * * *$ \\
\hline Long-term care insurance & - & 0.045 & - & -0.002 \\
\hline PIA & -0.000 & 0.000 & $-0.000 * *$ & -0.000 \\
\hline No educational degree & - & 0.035 & - & $0.020 *$ \\
\hline GED/high school degree & - & -0.024 & - & 0.002 \\
\hline Age & 0.001 & 0.001 & 0.001 & 0.001 \\
\hline Male & - & -0.021 & - & -0.000 \\
\hline Non-white & - & 0.003 & - & 0.006 \\
\hline Catholic & - & 0.040 & - & 0.004 \\
\hline County population less than 250,000 & - & 0.015 & - & 0.010 \\
\hline Midwest & -0.011 & -0.003 & 0.008 & 0.005 \\
\hline South & 0.005 & 0.014 & 0.002 & -0.002 \\
\hline West & -0.029 & -0.011 & -0.011 & -0.010 \\
\hline Number of observations & 535 & 535 & 2,615 & 2,615 \\
\hline
\end{tabular}

Notes: ${ }^{*} \mathrm{p}<0.10,{ }^{* *} \mathrm{p}<0.05,{ }^{* * *} \mathrm{p}<.01$. Significance is calculated using robust standard errors.

Source: Authors' calculation from the HRS, Waves 1-10. 
Table 8. Marginal Effects for Some Assistance with Financial Management, by Cognitive Impairment Status

\begin{tabular}{lcccc}
\hline & \multicolumn{2}{c}{ Imputed dementia } & \multicolumn{2}{c}{ Any sign of impairment } \\
\cline { 2 - 5 } & $(1)$ & $(2)$ & $(3)$ & $(4)$ \\
Any assistance & SSA & Full & SSA & Full \\
specification & \multicolumn{2}{c}{ specification } \\
\hline Warried & -0.003 & - & $0.057^{* *}$ & - \\
Widowed & -0.007 & - & -0.016 & - \\
Isolated & - & -0.011 & - & $-0.097^{* * *}$ \\
History of divorce/being widowed & - & 0.034 & - & -0.027 \\
Has children & - & -0.022 & - & 0.002 \\
Has unmarried children & - & 0.024 & - & $0.029^{*}$ \\
Long-term care insurance & - & -0.039 & - & -0.028 \\
PIA & 0.000 & 0.000 & 0.000 & -0.000 \\
No educational degree & - & -0.009 & - & $-0.067^{* * *}$ \\
GED/high school degree & - & 0.014 & - & $-0.044^{* *}$ \\
Age & $0.002^{*}$ & $0.002^{*}$ & $0.007^{* * *}$ & $0.005^{* * *}$ \\
Male & - & 0.023 & - & -0.002 \\
Non-white & - & $-0.053^{*}$ & - & $-0.069^{* * *}$ \\
Catholic & - & 0.013 & - & $0.034^{* *}$ \\
County population less than 250,000 & - & 0.006 & - & $0.027^{*}$ \\
Midwest & 0.028 & 0.025 & -0.020 & -0.022 \\
South & 0.032 & 0.034 & -0.022 & -0.010 \\
West & $0.048^{* *}$ & $0.043^{* *}$ & 0.017 & 0.023 \\
Number of observations & 535 & 535 & 2,615 & 2,615 \\
\hline
\end{tabular}

Notes: ${ }^{*} \mathrm{p}<0.10,{ }^{* *} \mathrm{p}<0.05,{ }^{* * *} \mathrm{p}<.01$. Significance is calculated using robust standard errors.

Source: Authors' calculation from the HRS, Waves 1-10. 


\section{RECENT WORKING PAPERS FROM THE CENTER FOR RETIREMENT RESEARCH AT BOSTON COLLEGE}

An Overview of the Pension/OPEB Landscape

Alicia H. Munnell and Jean-Pierre Aubry, October 2016

What Are the Effects of Doubling Up on Retirement Income and Assets?

Deirdre Pfeiffer, Katrin B. Anacker, and Brooks Louton, September 2016

How Does Student Debt Affect Early-Career Retirement Saving?

Matthew S. Rutledge, Geoffrey T. Sanzenbacher, and Francis M. Vitagliano, September 2016

The Labor Supply of Disabled Veterans: 1995-2014

Matthew S. Rutledge, Geoffrey T. Sanzenbacher, and Caroline V. Crawford, August 2016

The Mortality Effects of Retirement: Evidence from Social Security Eligibility at Age 62 Maria D. Fitzpatrick and Timothy J. Moore, August 2016

How Would Investing in Equities Have Affected the Social Security Trust Fund?

Gary Burtless, Anqi Chen, Wenliang Hou, Alicia H. Munnell, and Anthony Webb, July 2016

Are Early Claimers Making a Mistake?

Alicia H. Munnell, Geoffrey T. Sanzenbacher, Anthony Webb, and Christopher M. Gillis, July 2016

Marital Histories, Gender, and Financial Security in Late Mid-Life: Evidence from Four Cohorts in the Health and Retirement Study

Amelia Karraker and Cassandra Dorius, July 2016

Pension Participation, Wealth, and Income: 1992-2010

Alicia H. Munnell, Wenliang Hou, Anthony Webb, and Yinji Li, July 2016

The Interconnected Relationships of Health Insurance, Health, and Labor Market Outcomes

Matthew S. Rutledge, July 2016

Labor Force Dynamics in the Great Recession and Its Aftermath: Implications for Older Workers

Gary Burtless, July 2016

Elderly Poverty in the United States in the 21st Century: Exploring the Role of Assets in the Supplemental Poverty Measure

Christopher Wimer and Lucas Manfield, November 2015

All working papers are available on the Center for Retirement Research website (http://crr.bc.edu) and can be requested by e-mail (crr@bc.edu) or phone (617-552-1762). 